\author{
EWA ZAJDLER \\ Uniwersytet Jagielloński w Krakowie \\ e.zajdler@pro.onet.pl
}

\title{
Identifying the acoustic features in tonal phonemes in Chinese ${ }^{1}$
}

\begin{abstract}
The current paper refers to the particular phonetic and phonological substance of the Chinese language. The key topics include the acoustic features of tonal languages, speech sound and audio-perception, as well as some issues of acquisition of Chinese language skills and reception conditions. The difficulties in tonal phonemes identification in hearing-impaired native Chinese and in non-tonal language users learning Chinese as a foreign language inspire the scientists to research the register of tones, acoustic features of tonal languages, the fundamental frequency (F0), tone contour and duration, and the speech signal - natural and subjected to filtration.
\end{abstract}

KEYWORDS: Chinese; tonal languages; tones; tonal phonemes; Chinese language acquisition.

\section{THE CHINESE SYLLABLE}

Chinese is a tonal language, thus the difference in the tone is directly linked to the word meaning. Tones in Mandarin Chinese, like in other languages in Central, East and South-East Asia, such as Thai or Burmese (Fromkin et al. 2003), share the same typological feature alien to non-tonal language users, i.e. the sound pitch which is as distinctive as the components of segmental phonemes of the syllabic structure. The syllable cannot miss the tone, as it is an inherent part of the monosyllabic morpheme structure of Chinese. This also means that different words in Chinese written with the same or with a different character can be pronounced alike with a difference in the tone ( $\mathrm{Wu}$ 1993: 179-181; Jeng 1995: 257-276; Guo et al. 2010: 78).

${ }^{1}$ This research uses data collected in the National Central Library in Taipei, thanks to the research grant of the Center for Chinese Studies (CCS), Taiwan, R.O.C., 2013. 
The Chinese language is relatively poor in syllables. There are only about 404 (Jeng 1995) simple structure syllables in the Chinese language, all constructed in accordance with $(\mathrm{C}) \mathrm{V}(\mathrm{C})$ limits as a combination of optional consonants $(\mathrm{C})$ and obligatory vowels $(\mathrm{V})$. A comparison with the estimated at ca. 42 thousand syllables in the Polish language gives an idea of the need to differentiate the limited in number syllables in Chinese (Śledziński 2008: 231). Lee et al. call the $(C) \mathrm{V}(C)$ sound sequence base syllables and count them to as many as 408 . This results in a huge number of homophones and syllables forming confusing sets (Lee Y. et al. 1997: 75). "Tones in Chinese are defined in terms of the rhythmic rise and fall of pitch or the pitch counter of the voiced part of the character" (Leong 2006: 74).

\section{TONE AS A DISTINCTIVE PROPERTY}

Tone is a linguistic term. In phonological categories it means a suprasegmental feature which distinguishes two words with the same segmental structure of the syllable. It is due to tonal phonemes in Chinese that, according to Chao (1968), there are about 1,297 syllables, or 1300, as Lee et al. (1997) quoted. With regard to monosyllabic morphemes and the relatively high rate of recurrence of mono- and bi-syllabic vocabulary, there is a clear distinction between syllables, which determines verbal communication. Tones have always been an integral part of the sound in the Chinese language. Three out of the four original traditional Chinese tones are distributed into four tones of the Modern Mandarin Chinese (Xie 1994: 32-37) in all the standards: Continental Standard Chinese, Taiwan Standard Chinese, Hong Kong Standard Chinese and Singapore Standard Chinese (Künstler 2000: 18,270-271; Kratochvil 1968: 24). The relative position in pitch frequency of the four Chinese isolated tones is scaled in a five-point scale (time-pitch grasp) introduced by Chao (1968) to show the pitch contours of the tones.

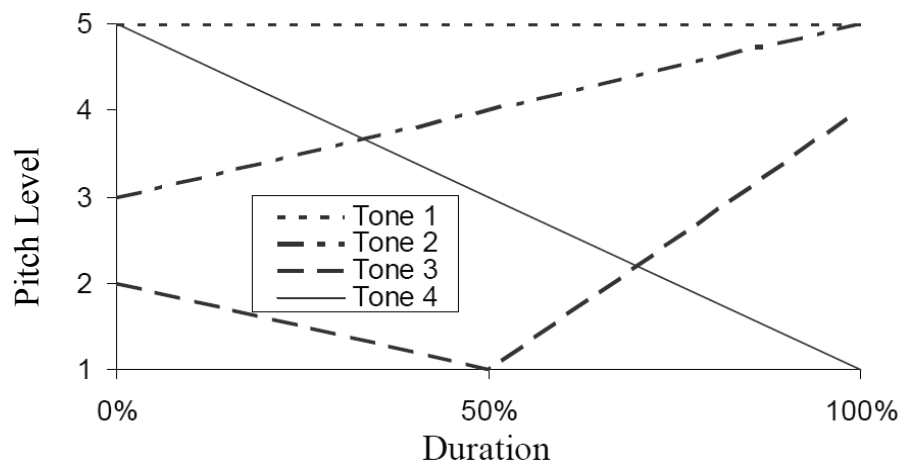


The sequences of the numbers represent the tones, the level tone (55), the rising tone (35), the falling-rising tone (214) and the falling tone (51). Two more sandhi tones related to the morphological structure of Chinese words should be added, with contours 53 (when 51 is preceding 51, as in 看見 kànjiàn 'see' or 大陸 dàlù 'continent') and 21 (when 214 is preceding tones 55, 35 or 51, as in 老大lăodà 'the eldest son') (Chao 1968: 25-29; Kratochvil 1968: $38-39,41)$. However, since the falling-rising tone 214 is also changing into the rising tone 35 (as in老早lăozăo 'dawno temu' lăo changes into láo), it correlates with the original rising tone and thus does not add one more contour to the Mandarin Chinese tones.

\section{ACOUSTIC FEATURES OF THE TONE}

The tone duration depends on the vowel/vowels of the syllable rather than on the contour changes. However, two pairs (T1 and T3 vs. T2 and T4) of long and short time pronunciation are sometimes suggested. It is important to stress that the modern Chinese, similarly to other languages or dialects in the region, does not have the phonological opposition of length (short : long) (Künstler 2000: 227). Though the syllabic structure of Chinese is simple, the vocality essential for the tones is common for Mandarin languages. Künstler (2000: 272) writes "The vocalism of Mandarin languages $(. .$.$) is relatively rich: apart from vowels, there are large inventories$ of diphthongs and triphthongs, with tendencies to diphthongize simple vowels and to triphthongize diphthongs dominating" (translated by prof. Majewicz A.F.).

The F0 is the lowest frequency in the sound spectrum. In Chinese, the tones' F0 range is relative and subjected to a personal voice scope and changes within the tone contour. Therefore, it varies from one person to another, lower for a male and higher for a female and a child. Following the reports, a female f0 operates between $180 \mathrm{~Hz}$ and $270 \mathrm{~Hz}$ when pronouncing the syllable $m a$ in four Chinese tones (Jongman et al. 2006: 211). The average means of f0 from another study carried out by Xu (1997: 67) run from about $90 \mathrm{~Hz}$ to slightly above $140 \mathrm{~Hz}$. Given the fact that a loss of the speech sound spectrum below $350 \mathrm{~Hz}$ in Polish results in a loss of only $2 \%$ speech clarity, it can be concluded that the Polish recipient with no hearing problems does not attach particular importance to the reception of low frequency sounds in speech. In some way high exposure to speech frequency within the $400 \mathrm{~Hz}-$ $4000 \mathrm{~Hz}$ spectrum, relevant to comprehend the Polish language, does not endow the recipient with sufficient sensitivity to bass and treble sounds (Hojan \& Skrodzka 2005: 104-105). 


\section{FROM THE PHONE TO THE PHONEME}

The physiological frequency range of phonation provides a register in which vocal functions of the native speakers of Mandarin Chinese allow exceeding the maximum range of non-tonal language speakers (Chen Sheng Hwa 1996: 79-86). Phonation is mutually related to hearing ability, its range being greater in Chinese native speakers compared to non-tonal language users. The pitch range of native Chinese and English speakers tested on both, English and Chinese language utterance, differs in favor of the Chinese with a 1.5 times wider range when compared to the English speaking English, and a slightly wider range in the case of the English speaking Chinese (Wang et al. 2006: 250).

This is a perfect starting point to turn from the acoustic sound features to the meaning. Effective hearing of the sound's pitch and contour distinction are prior to processing the speech signal into meaning. According to the related papers, there are some acoustic features of speech sound in Mandarin Chinese which strongly condition tone processing and identification. In order to understand the mechanisms responsible for the native hearingimpaired and non-native speakers' problems with tone identification, the acoustic features of tones were extracted in syllables using new technology tools and subjected to identification tasks. Syllables naturally produced by native speakers, both in isolation and context, normalized, synthesized, extended and/or transmitted through low-pass acoustic filters preserve the feature expected to play the main role in sound processing. The rates of proper tones identification compared to one another give an answer to which acoustic cue is more distinctive to the other.

The sequence Chinese children acquire tones highly correlates with nonnative users learning to identify tones. Basically, research provides us with evidence that the first and fourth tones are easier to be grasped, while the second and third tones are acquired later, yet mutually confused for the longtime acquisition process in L1 (Li \& Thompson 1977: 185; Chang et al. 2004: 225, 237-238; Tseng C.-C.et al. 2007: 43-69). The mistaking of T2 and T3 seems to be a common problem for both, hearing-impaired children - users of Mandarin, and foreign learners (Guo et al. 2010: 80). Mandarin speaking hearing-impaired children experience inefficiency of auditory perception and tone recognition due to processing the lexical tones in a limited scope of register. At that very point they show similar difficulties in tone judgment to users of non-tonal languages, when learning Chinese.

The experiments on a flattened pitch contour (a monotone speech) of Chinese syllables were preceded with stimuli prepared as synthesized 
speech. The tasks of lexical identification, tone restoration of monotone disyllabic stimuli in Chinese (meaningful words, meaningless non-syllables and non-words) and transcribed F0 flattened and F0 intact re-synthesized sentences, allowed to evaluate intelligibility of monotone syllabic words to native speakers of Mandarin. The results of the experiments revealed differentiation in the reaction time and intelligibility scores, depending on the kind of stimulus, as well as great difficulty to restore the original tone and grasp the information conveyed in stimuli data (Jeng 1994: 175-196). It becomes clear in auditory lexical decision tasks that, in a tonal language, the pitch contour as a lexical tone is a factor of fundamental frequency which is responsible for encoding information. Those learning Chinese as a foreign language have to face difficulty to recognize the pitch contour within the register not present in their non-tonal L1.

Chang (2007: 101) recalling different studies arranges the tone identification difficulty degree as T1, T3, T4 and T2 for English speakers (after: Wang et al. 1999) and T1, T4, T2, T3 for, generally, non-tonal language speakers (after: Petrushin 2000). Although the difference in the position of T2 in tones' order may come from a number of objects in an experiment, numerous research studies point to T2 as the tone most easily confused with the three other tones. This is the case for native speakers of Mandarin, considering both normal-hearing and hearing impaired children according to the experiment carried out in a significant group of primary school students. An additional result of Chang's tone discrimination study states the tone's difficulty degree as following: T2, T3, T1 and T4 (Chang 2007b: 101, 115)

The acoustic features of tones are unfamiliar to native users of non-tonal languages. Chen Gwang-tsai (1975: 25-27) draws attention to the pairs of tones when teaching foreigners Chinese, i.e. high and low, rising and falling. There is a discussion among researchers as to the tone duration, especially with regard to the third tone as the longest one. The third tone is longer than the other tones, while the fourth tone is the shortest. However, the third tone may be regarded as the shortest when the pitch contour 214 becomes 21 (Chao 1968; Jeng 1995; Xu 1997). The differences in data are probably caused by differences in preparing the sound samples. Guo et al. (2010) further specify three parameters of the contour: the initial frequency of F0 contour, the moment of the contour turning point in the tone duration and the initial falling shape. According to this explanation, the contour and the time of turning point in the course of change in fundamental frequency seem to be crucial for the discrimination between the second and third tones. The fundamental frequency contour of the second tone decreases to $25 \%-30 \%$ of the time period, then rises. $\mathrm{Xu}$ (1997) points out that the turning point of the 
second tone is observed in the onset of the syllable. The frequency falling down period is too short to be easily identified by human ear, so it is somehow ignored and the frequency rising period within $75 \%$ of time plays a significant role. The fundamental frequency contour of the third tone decreases in the $75 \%$ of the time, to rise again in the ending $25 \%$ of time. The two tones also differ in the degree of the initial fall. These two factors, i.e. the degree of initial fall and its duration before the turning point, making the switch point perceivable (for T3) or hardly perceivable (for T2), seem to be crucial for native speakers in identifying tones. Therefore, the pitch contour regarding the differences in fall and rise within sound duration contributes to the differences in tone and sound discrimination (Guo et al. 2010: 79; Chang 2007b: 99-100). These, as Xu says, canonical form of tones "will be distorted by various factors, including the adjacent onset and offset values of the neighboring tones" (Xu 1997: 67). Yet, Chang (2007b: 100) refers to Garding et al. (1989) and compares T3 and T4 regarding contour falling in terms of timing and diapason. When discussed as half-third tone omitting the tone's rising, these features differentiate the falling contours of the two tones.

\section{CONCLUSION}

Concluding, the tonal phonemes present in the Chinese language lack a counterpart in non-tonal first languages of learners. Limited natural feedback determines auditory perceptual sensitivity. In order to understand the nature of challenge faced by an adult learner of Mandarin Chinese, the basis of neuro-processing needs to be taken into consideration. According to Wang et al. (2006: 250) tones along with segmental properties, in the case of native users, are naturally, predominantly but not exclusively, processed in the left hemisphere. Being decoded as a non-linguistic feature - tones operate in the right hemisphere region, at least at the beginning of learning Chinese as a foreign language. There is, however a competition for both, native and non-native users, between the auditory (initial) and linguistic (effective for the meaning) processing of tones. The functional contribution of the F0 contour to the segmental structure draws attention to psychoacoustics (2006: 50). A wide range of studies contribute significantly to the understanding of acoustic parameters of the speech signal in Mandarin. When applied to the Chinese language teaching to Polish students, the broad knowledge of tones requires confronting with the studies on audioperception and decoding by users of Polish as L1. 


\section{REFERENCES}

Chang Hsiao-Fen張小芬. 2007b. 電腦化「國語聲調聽辨測驗 」之編製. 聽辨測驗. 54(1), 97-120.

Chang Hsiao-Fen 張小芬 / Gu Hung-Yan古鴻炎 / Wu Jiun-Hsin吳俊欣. 2004. 「聽障學生國語 語詞聲調人耳評分與電腦分析之初探」特殊教育研究學刊. 26, 221-245.

Chao, Yuan Ren 趙元任 . 1968. A Grammar of Spoken Chinese (chiń. Zhōngguóhuàde wénfă 中国 话的文法). Berkeley.

Chen, Gwang-tsai. 1975. Tone pair. Journal of Chinese Language Teachers Association. Vol. 10. (1), 25-27.

Chen, Sheng Hwa 1996. Voice range profile of Taiwanese normal young adults: a preliminary study. 聽語會刊 1996.12. 79-86

Fromkin, V. / Rodman, R. / Hyams, N. 2003. An introduction to language. Boston: Thomson/Heinle Publication.

Garding, E./ Kratochvil, P. / Svantesson, J.O. / Zhang, J. 1986. Tone 4 and Tone 3 discrimination in modern standard Chinese. Language and Speech, 29, 281-293.

Guo Jyun-Hong郭俊弘 / Liu Huei-Mei劉惠美 / Hung Kuei-Chun黃桂君 / Wang Hsiao-Chuan 王小川 / Tsao Feng-Ming曹峰銘. 2010. 修改語音基頻曲線與低通濾波處理影響聽障學生國 語聲調聽辨成效之研究. 特殊教育研究學刊, 35(3), 77-101.

Hojan, E. \& Skrodzka, E. 2005. Audiologiczne aspektu akustyki i psychoakustyki. In: M. Śliwińska-Kowalska (ed.). Audiologia kliniczna. Łódź, 97-106.

Jeng, J. L.鄭傑麟. 1995. 國語聲調音位的探究. 屏東教大學報.8.257-276.

Jeng Jing-Yi 鄭靜宜 1994. 語音單調化對國語詞語和句子的辨識及語音清晰度的影響. 南師學報 38, 1, 175-196.

Jongman, A. / Wang, Y. / Moore, C.B. / Sereno J. A. 2006. Perception and Production of Mandarin Chinese tones. In: Li P. / Tan L.H. / Bates E. / Tzeng O.J.L. The Handbook of East Asian Psycholinguistics. Vol. 1. Chinese. Cambridge University Press, 209-217.

Kratochvil, P. 1968. The Chinese Language Today. London: Hutchinson University Library.

Künstler, M.J. 2000. Języki chińskie. Warszawa: Wydawnictwo Akademickie Dialog.

Lee, Y. / Lee, Lin-shan / Tseng, Chiu-yu. 1997. Isolated Mandarin Syllable Recognition with Limited Training Data Specially Considering the Effect of Tones. IEEE Transactions on Speech and Audio Processing, 5(1), 75-80.

Leong, C. K. 2006. Making explicit children's implicit epilanguage in learning to read Chinese. In: Li P. / Tan L.H. / Bates E. / Tzeng O.J.L. The Handbook of East Asian Psycholinguistics. Vol. 1. Chinese. Cambridge University Press, 70-80.

Li, C. N., / Thompson, S. A. 1977. The acquisition of tone in Mandarin-speaking children. Journal of Child Language, 4, 185-199.

Petrushin, V.A. 2000. Student response evaluation for spoken language learning: case study of learnig Chinese tones. IEEE-International conference advanced learning technologies, 9, 9-12.

Shen, X. S. 1989. Toward a register approach in teaching Mandarin tones. Journal of Chinese Language Teachers Association, 24, 27-47.

Śledziński D. 2008. Fonetyczno-akustyczna analiza struktury sylaby w języku polskim na potrzeby technologii mowy, Investigationes Linguisticae, vol. XVI, Poznań.

Tseng Chin-Chin曾金金 / Chang Yue-Hsin張月馨 / Chen Ching-Tzu陳靜子. 2007. 線上聽辨聲 調自我檢測系統效果評估.華語文教學研究, 12, 43-69.

Wang, Y. / Jongman A. / Sereno J.A. 2006. L2 Acquisition and Processing of Mandarin Tone. In: Li P. / Tan L.H. / Bates E. / Tzeng O.J.L. The Handbook of East Asian Psycholinguistics. Vol. 1. Chinese. Cambridge University Press. 250-256. 
Wang, Y. / Spence, M.M. / Jongman, A. / Sereno, J.A. 1999. Training American listeners to perceive Mandarin tones. Journal of the Acoustical Society of America, 12, 106, 3649-3658.

Wu Jing-lan. 1993.The acquisition of Mandarin tones. Research Papers in Linguistics and Literature, 2, 179-188.

Xie Yun Fei謝雲飛. 1994. 四聲八調與八調不全. 中國語文, 10, 32-37.

Xu, Y. 1997. Contextual tonal variations in Mandarin. Journal of Phonetics, 25, 61-83. 